\section{Estudo \\ cobebate}

em Cestão

Planejamento
Revista Estudo \& Debate, Lajeado, v. 27, n. 3, 2020. ISSN 1983-036X

DOI: http://dx.doi.org/10.22410/issn.1983-036X.v27i3a2020.2531

\title{
LUGAR DE MULHER É ONDE ELA QUISER: OS DESAFIOS DAS MULHERES NO MERCADO DE TRABALHO DOS AGRONEGÓCIOS
}

\author{
Brenda Ribeiro da Silva ${ }^{1}$, Ezequiel Redin ${ }^{2}$
}

\begin{abstract}
Resumo: A pesquisa objetiva analisar e compreender a atuação das mulheres que ocupam cargos no âmbito comercial em organizaçôes dos agronegócios, bem como, investigar a relação das mulheres com os desafios enfrentados no mercado de trabalho na regiáo de Unaí, Minas Gerais. Para tanto, foi realizado um roteiro semiestruturado de cunho qualitativo para o levantamento das informaçóes. No estudo de caso, foram entrevistadas dez mulheres que atuam em organizaçóes relacionadas aos agronegócios. Os resultados da pesquisa apontam que as mulheres entrevistadas são, majoritariamente solteiras, jovens, provenientes de famílias de baixa renda e relativamente novas em seus cargos, possuindo um padrão salarial razoável e determinado pelo tempo de trabalho na empresa. Porém, possuíram dificuldades para ingresso no mercado de trabalho no campo dos agronegócios. Demonstrou que as mulheres entrevistadas procuram independência pessoal, através de muita dedicação, trabalho e foco em seus projetos de vida. Foi possível verificar que a dominação masculina permeia suas vidas de forma constante, desde o seio familiar, na graduação, nos ambientes de trabalho e até mesmo em relacionamentos pessoais. Com as informações da pesquisa foi possível definir três tipologias em relação as mulheres profissionais entrevistadas: a) profissionais de cargos iniciais em empresas dos agronegócios; b) profissionais de cargos intermediários em empresas dos agronegócios; c) profissionais consolidadas em empresas dos agronegócios. A pesquisa demonstrou que as mulheres almejam o protagonismo e empoderamento de outras mulheres, não somente no setor de trabalho dos agronegócios, mas em todos os outros postos de trabalho. Portanto, é necessário promover políticas públicas e açôes informativas, com a cooperação do setor privado no intuito de demonstrar cada vez mais a visibilidade feminina no mundo do mercado de trabalho dos agronegócios.
\end{abstract}

Palavras-chave: agropecuária, organizaçóes, participação feminina, profissionais, trabalhadoras.

1 Engenheira Agrônoma pela Universidade Federal dos Vales do Jequitinhonha e Mucuri, Unaí, Minas Gerais.

2 Curso Superior de Tecnologia em Agropecuária: Sistemas de Produção (UERGS) - CREA RS 160488; Bacharelado em Administração (ULBRA); Licenciatura plena para a Educação Profissional (UFSM); Licenciatura em Filosofia (UFSM); Pós-graduação em Gestão Pública Municipal (UFSM); Pós-graduação em Tecnologias de Informação e Comunicação aplicadas à Educação (UFSM); Pós-graduação em Ensino de Sociologia no Ensino Médio (UFSM); Pós-graduação em Ensino de Filosofia no Ensino Médio (UFSM); Mestrado e Doutorado em Extensão Rural (PPGExR/UFSM); Editor da Revista Extensão Rural. Professor do Instituto de Ciências Agrárias (ICA) da Universidade Federal dos Vales do Jequitinhonha e Mucuri (UFVJM), Campus Unaí, MG e Professor Permanente e Vice Coordenador do Programa de Pós-graduação em Estudos Rurais (PPGER) da Universidade Federal dos Vales do Jequitinhonha e Mucuri (UFVJM), Campus Diamantina, MG. 


\title{
WOMAN'S PLACE IS WHERE SHE WANTS: THE CHALLENGES OF WOMEN IN THE AGRIBUSINESS LABOR MARKET
}

\begin{abstract}
The research aims to analyze and understand the role of women who occupy positions in the commercial sphere in agribusiness organizations, as well as, investigate the relationship of women with the challenges faced in the labor market in the region of Unaí, Minas Gerais. To this end, a semi-structured script of qualitative nature was used to collect the information. In the case study, ten women who work in organizations related to agribusiness were interviewed. The survey results show that the women interviewed are, mostly single, young, from low-income families and relatively new in their positions, having a reasonable salary pattern and determined by the time of work in the company. However, they had difficulties to enter the labor market in the field of agribusiness. It demonstrated that the women interviewed seek personal independence, through a lot of dedication, work and focus on their life projects. It was possible to verify that male domination constantly permeates their lives, from the family, at graduation, in the workplace and even in personal relationships. With the research information, it was possible to define three types in relation to the professional women interviewed: a) professionals from initial positions in agribusiness companies; b) professionals in intermediate positions in agribusiness companies; c) consolidated professionals in agribusiness companies. Research has shown that women crave the role and empowerment of other women, not only in the agribusiness sector, but in all other jobs. Therefore, it is necessary to promote public policies and information actions, with the cooperation of the private sector in order to increasingly demonstrate the visibility of women in the world of the agribusiness labor market.
\end{abstract}

Keywords: agriculture, organizations, female participation, professionals, workers.

\section{INTRODUÇÃO}

Esta pesquisa trata de uma temática contemporânea no mundo dos agronegócios, porém, com forte enraizamento histórico e cultural, ou seja, as mulheres no mercado de trabalho nos agronegócios. Conforme Barros et al (2019), analisando os rendimentos médios entre homens e mulheres empregados nos agronegócios, verificou-se uma diferença, em termos absolutos, de $\mathrm{R} \$ 149,04$ em favor da mão de obra masculina em 2004/05ou uma diferença percentual de $27,39 \%$ - e de $\mathrm{R} \$ 227,25$ em $2014 / 15$ ou de $26,84 \%$ (BARROS et al, 2019).

Além da questão salarial há várias dificuldades relacionadas a inserção da mulher em um contexto de trabalho majoritariamente dominado pelo homem, em especial, quando o prestígio social das atividades relacionadas ao setor agropecuário foi, historicamente, atribuído ao sexo masculino. Nesse sentido, Bourdieu (2011), sociólogo francês, sustenta que a dominação masculina é uma dominação simbólica construída socialmente e reproduzida historicamente através do habitus de homens dominantes e mulheres submissas (BOURDIEU, 2011). No meio rural ou em atividades relacionadas aos bens e serviços voltados ao campo essa relação de dominaçáo masculina é presente e se reproduz acentuadamente.

Há estudos relacionados a juventude rural, em especial, que afirmam que as moças do meio rural optam por cursos superiores desvinculados das ciências rurais, por uma série de motivos ligados a penosidade do trabalho rural e pelo status sobre cursos considerados urbanos (REDIN, 2012). Em alguns momentos da história as próprias mulheres negaram a condição de serem protagonistas no campo dos agronegócios em função das convençóes sociais previamente estabelecidas. No entanto, há uma fase em consolidação entre as 
mulheres, sejam elas de origem rural ou urbana, que buscam uma formação superior na área das ciências agrárias. Há ainda, conforme estudo de Figueiredo et al (2016), as mulheres recém-formadas em cursos de agronomia que desistem de atuarem na profissão, adotando outras funções, às vezes, abaixo de sua qualificação profissional com baixos retornos sociais e econômicos (FIGUEIREDO et al, 2016). Por outro lado, há aquelas que ganham espaço no âmbito do mercado de trabalho, com formação superior nas ciências agrárias, que protagonizam um espaço de empoderamento e trabalho nas organizações que possuem um portfólio de bens e serviços voltados ao meio rural brasileiro.

Apesar disso, ainda existem visões conservadoras sobre a inserção de mulheres no mercado de trabalho nos agronegócios. Yannoulas (2002), em um estudo sobre a situação das políticas públicas e relaçóes de gênero no mercado de trabalho, sustenta que as discriminações recaem, principalmente, na constituição fragilizada da subjetividade feminina, assim como na escolha por parte das mulheres de profissóes e ocupaçóes pouco prestigiadas e mal remuneradas. No âmbito profissional, há impedimentos ao acesso e promoção no emprego, salários inferiores e ocorrem dificuldades para ascensão profissional em virtude de responsabilidades familiares, maior entrave para aceitação no mercado ou até mesmo demissão por causa da maternidade, assédio sexual, entre outras questóes (YANNOULAS, 2002). Nesse contexto, esse trabalho foca nas mulheres que, atualmente, atuam em cargos de gestão em empresas relacionadas aos agronegócios, um perfil de mulher protagonista e que superou, em boa parte, muitas barreiras impostas pela herança cunhada pela falta de confiança e credibilidade na figura feminina.

Os desafios das mulheres no mercado de trabalho são distintos, em especial, pela existência de uma herança sexista e cosmopolita. Esta investigação concentra-se na mesorregião do Noroeste de Minas Gerais, em especial, no município de Unaí que é um polo na produção agropecuária e de destaque no âmbito da expansão do desenvolvimento no Brasil. Nesta região, concentrou-se muitos complexos agroindustriais que movimentam o mercado de bens e serviços voltados para a área rural. Além disso, existem Instituiçóes de Ensino Superior e Institutos Federais que oferecem cursos superiores e formação técnica voltados para os agronegócios. Nesse cenário, o interesse e o protagonismo feminino crescem cada vez mais na regiáo em detrimento das oportunidades oferecidas pelas empresas privadas e pelas instituições públicas de Assistência Técnica e Extensão Rural (ATER) presentes, além de possibilidades no âmbito do ensino e também como agricultoras.

É possível observar no espaço urbano de Unaí, mulheres com uniformes de empresas comerciais da área e, em diversas revendas locais, há a presença feminina nos setores dos agronegócios. Logo, a pesquisa desenvolvida na região tem potencial para avaliar a atuação das mulheres no contexto das cadeias agroindustriais relacionadas ao setor agropecuário na região. Portanto, este trabalho objetiva analisar e compreender a atuação das mulheres que ocupam cargos no âmbito comercial em organizaçóes dos agronegócios, bem como, investigar a relação das mulheres com os desafios enfrentados no mercado de trabalho na regiāo de Unaí, Minas Gerais.

Após essa introdução, abordam-se as principais pesquisas relacionadas as mulheres no setor, suas reflexóes sobre o mercado de trabalho e a divisão social do espaço da mulher. Posteriormente, apresenta-se a metodologia da pesquisa que serviu como base principal 
para a investigação, compilando com outros estudos anteriores e confrontando com os casos analisados. $\mathrm{Na}$ sequência, os resultados, de cunham qualitativo, apresentam reflexóes sobre a condição da mulher profissional no setor dos agronegócios. Por último, são tecidas as consideraçóes finais que permitem elaborar uma linha de pensamentos mais específica sobre a atuação das mulheres nos agronegócios da região de Unaí.

\section{REFERENCIAL TEÓRICO}

\subsection{A DIVISÁO SOCIAL DO TRABALHO E A QUESTÁO DE GÊNERO}

Por muito tempo, a divisão social do trabalho com relação ao gênero foi de concreta relação em que o homem ocuparia cargos mais importantes e consequentemente com salários melhores, enquanto mulheres ocupavam cargos de menor importância e com salários menores. Tal relação de causa-efeito fez parte da lógica histórica em quase todas as formas de trabalho. Para Araújo e Ribeiro (2001) quando não há uma avaliação correta dos diferentes custos e benefícios produtivos de cada pessoa, sendo feita apenas a partir de uma avaliação através de percepções que se tenham, é considerado um tipo de discriminação.

No âmbito dos agronegócios não é perceptível mulheres ocupando grandes cargos, seja em empresas agroindustriais ou em fazendas. Esse papel é atribuído geralmente aos homens, considerados com "melhor capacidade" para gestão. Ainda que, atualmente, houve modificações nesse contexto e as mulheres tenham se destacado no mercado de trabalho com atuação em cargos de alta gerência, a discriminação acontece através do fato que, muitas vezes, a remuneração é menor em comparação ao sexo masculino. Essa divisão de gênero perpetuou por muitos anos e ainda perpetua em diversas situaçóes.

No Brasil essa realidade se torna marcante, pois as soberanias masculinas nos cargos de organizaçóes estão gerando uma série de desigualdades de gênero, principalmente, na área dos agronegócios. Carreira, Ajamil e Moreira (2001) dizem que entre as barreiras impostas na liderança feminina destaca-se o âmbito patriarcal, no qual ressalta os homens em relação às mulheres e a partir disso surgem as desigualdades sociais, culturais e econômicas existentes entre os diferentes sexos. Independente da existência de discursos sobre igualdade de oportunidades, os entraves são visíveis relativos à participação das mulheres no ambiente de trabalho, sendo com relação à remuneração, aceitação e inclusive sobre exercer algumas funçōes.

Entretanto, a expansão econômica também trouxe fatores negativos sobre o papel da mulher em que passou a ser fonte de exploração dos industriais, que exigiam uma jornada de trabalho excessiva, cerca de 17 horas diárias em condiçóes sub-humanas e a baixos salários, quase $60 \%$ inferior ao dos homens. Nesse sentido, com a escassez de mão de obra masculina, as mulheres, passaram a ser utilizadas para baratear os salários, além de serem consideradas como um grupo mais fácil de se disciplinar (BAYLÃO e SCHETTINO, 2014; CARRIJO e FERREIRA, 2017).

A realidade, atualmente, não é mais a mesma, porém, a discriminação com a mulher ainda existe, apesar de silenciosa, oculta e presente nas estruturas sociais. A mulher, com diversas lutas sociais, conquistou maior participação no mercado de trabalho e na sociedade. 
Bruschini (1998) afirma que, apesar da sobrecarga de trabalho atribuída a mulher, dado o impacto da escolaridade e dos novos padróes demográficos e culturais, ocorreu elevação nas taxas de participação das mulheres que investiram na formação e, com isso, iniciou-se um processo de preparação para assumir cargos de comando em profissóes de prestígio e bons empregos nas instituiçóes financeiras e bancárias, bem como, a serem proprietárias de negócios no comércio e nos serviços. Esse processo contribuiu, em parte, para diminuir os índices de desvalorização feminina salarial e empresarial.

Conforme Vila (2019, p. 15), “a diversidade articulada de forma integrada será o caminho do futuro dessas mulheres, que precisa do equilíbrio entre avanço tecnológico, uso inteligente e responsável dos recursos naturais e sincronização entre povos, gêneros, profissóes e geraçóes". Dado o desenvolvimento das mulheres no mercado de trabalho, onde buscam melhores oportunidades e reconhecimento, parte-se para analisar outros aspectos desse processo. $\mathrm{Na}$ próxima seção, são discutidas as principais pesquisas sobre gênero e o trabalho na área de agronegócios.

\subsection{AS PESQUISAS SOBRE AS MULHERES NO CAMPO DOS AGRONEGÓCIOS}

Diante do crescimento do setor dos agronegócios no Brasil, concomitantemente, houve a necessidade de crescimento, procura e legitimação do espaço feminino. As mulheres que buscam um destaque na profissão estão crescentemente, mais protagonistas nas organizaçóes e nas suas respectivas posiçóes. A empresa Corteva agriscience realizou uma pesquisa com mais de quatro mil agricultoras em 2018, em 17 países, onde essas mulheres dizem que a discriminação de gênero persiste e ainda é uma barreira. $\mathrm{Na}$ investigação, as mulheres alegam que visualizaram o progresso, mesmo que de forma lenta. Com relação ao Brasil, a pesquisa relatou que $90 \%$ das brasileiras têm orgulho de trabalhar no campo ou na indústria agrícola. Esses resultados demonstram que, de certa forma, a mulher brasileira tem condiçóes de disputar igualmente ao homem no que tange aos conhecimentos, habilidades e atitudes para desempenhar as funçóes de gestão nas organizaçóes dos agronegócios.

Ressalta-se que o número de mulheres que ingressam no mercado de trabalho está aumentando, reduzindo bastante a pobreza e a desigualdade. No entanto, esse processo ocorreu e está ocorrendo muito lentamente devido aos inúmeros desafios que o trabalho nesse campo enfrenta. Esse empoderamento das mulheres no mercado de trabalho reduz a dependência e proporciona maior liberdade no campo profissional e na família.

Segundo Lavinas e Léon (2002), a inserção da mulher em mercados de trabalho ocorreu de forma natural, diante do desenvolvimento da sociedade, mas que não prescindia ser promovido. Em outras palavras, para os autores, a mulher seria inserida, mas não de forma tão crescente a ponto, por exemplo, de ocupar grandes cargos. Uma das consequências de se inserir a mulher no mercado de trabalho foi a alteração dos arranjos familiares já que, atualmente, as mulheres estão mais qualificadas para o trabalho, mais independentes economicamente e isso modifica a visão antepassada de dependência masculina e familiar. Outras questóes que influenciaram o processo de fortalecimento da mulher no mercado de trabalho envolvem a valorização da educação formal de nível universitário, a valorização da 
habilidade no relacionamento pessoal e da facilidade de adaptação às novas formas flexíveis de gestão (LAVINAS e LÉON, 2002).

Barros et al (2018), através do Centro de Estudos Avançados em Economia Aplicada (CEPEA), divulgou uma série de estudos com o intuito de compreender a presença feminina no campo, tanto da porteira das fazendas para dentro quanto para fora dela, incluindo assim agroindústrias, transporte e outras áreas correlacionadas. Nesse estudo, constatou-se que entre 2004 e 2015 o número de mulheres inseridas no agronegócio aumentou 8,3\%. Ainda demonstraram que as vagas femininas ocupadas são melhores, uma vez que nesse período de estudo, a participação das mulheres com ensino superior na área subiu de 7,6\% para 15\%. As que possuíam ensino médio completo, que antes representavam $31 \%$ do total foram para $42 \%$.

Isso enfatiza que essas mulheres estão cada vez mais buscando conhecimento para conquistar um espaço no mercado de trabalho. Nesse sentido, Cordeiro et al (2019) destacase que as mulheres ligadas ao setor dos agronegócios podem produzir, liderar, empregando sua inteligência e capacidade no sentido de obter conhecimento, manter-se atualizada e se inspirar nas experiências do associativismo e cooperativismo.

Jonathan (2005) afirma que no Brasil é significativo o número atual de empresas em áreas no geral, lideradas por mulheres que buscam se incluir e permanecer no mercado, assim como gerar empregos e contribuir para o desenvolvimento do país. Com relação às cooperativas, em 2018 as estatísticas do Sistema de Organização das Cooperativas do Brasil (OCB) demonstram que as mulheres representam cerca de $30 \%$ dos cooperados e $40 \%$ do quadro de empregados das cooperativas brasileiras.

Nos últimos anos, a participação das mulheres no setor dos agronegócios é crescente, bem como, proporcionaram indicadores relevantes para o avanço e protagonismo das mulheres no mercado de trabalho. Na próxima parte, são explorados os principais desafios que as mulheres enfrentam no setor agropecuário e suas visóes sobre o mundo.

\subsection{OS DESAFIOS E PERSPECTIVAS DAS MULHERES NO ÂMBITO DOS AGRONEGÓCIOS}

As mulheres inseridas em postos de trabalho nos agronegócios desempenham um papel primordial no desenvolvimento econômico do país, sendo inclusive responsáveis por muitos novos negócios criados atualmente. Porém, ainda há desafios pela frente, tanto para aquelas que já estão inseridas nesse mercado de trabalho, quanto para as que pretendem ingressar. Os desafios envolvem a consolidação dos seus direitos na sociedade e a conciliação dos seus papéis no seio da família e dos negócios.

As mulheres que buscam quebrar paradigmas nos agronegócios têm características psicológicas relacionadas a força e a perseverança. Diante de situações discriminatórias, acima de tudo, se sobressaem e continuam com os seus objetivos profissionais. Nesse sentido, há alegaçóes que afirmam que a chave para o sucesso neste caso está relacionada com a sua história de vida. Campos (2019, p. 136) afirma: "o sucesso chega até você quando a sua trajetória é construída com honestidade, quando você não se vitimiza e está disposta a pagar o preço do crescimento". 
As diferenças de gênero no meio rural brasileiro se incluem num aglomerado de outras desigualdades sociais que são consideradas, por vezes, insignificantes pela sociedade no que diz respeito ao dia a dia das mulheres (RAMOS, 2014). A mulher com a inserçáo no mercado de trabalho passou a possuir maior disposição para trabalhar, insistindo mais, possuindo mais participação, possibilitando trabalho em equipe e solução de problemas impostos. Esse comportamento possibilitou as mulheres a oportunidade de criarem uma forma própria de gestão, propriamente dita feminina, ao invés de se ajustarem ao padrão de gestão antigo, o que evidencia uma forma de gestão distinta (MACHADO, 2002).

Segundo Cordeiro et al (2019), as mulheres dos agronegócios estão em um processo de empoderamento no mercado de trabalho e conseguiram romper com várias barreiras do preconceito e estereótipos. Para Karpinski (2017), os desafios enfrentados envolvem a divisão social e cultural do trabalho e da produção de renda dessas mulheres. Os avanços são consideráveis, porém ainda há um longo caminho em função que um dos reflexos dessa repressão é que, embora desempenhem função importante na propriedade, em muitos casos ainda não se veem como protagonistas (KARPINSKI, 2017).

\section{METODOLOGIA}

Para compreensão da questão de pesquisa realizou-se uma investigaçáo de caráter qualitativo, entre os meses de outubro e novembro de 2019, utilizando-se um roteiro semiestruturado como instrumento de coleta de dados. A coleta de informaçóes foi realizada através de entrevistas de campo e, quando houve a impossibilidade de a entrevista ocorrer pessoalmente, foram feitas por correio eletrônico, totalizando $50 \%$ das entrevistas de forma presencial e $50 \%$ de forma digital. A seleção das entrevistadas foi realizada de forma aleatória e por conveniência, sendo que a amostra totalizou dez mulheres que trabalham em organizaçōes ligadas aos agronegócios no município de Unaí e região. Como requisito para a seleçáo das entrevistadas, em especial, foram selecionadas aquelas que estavam inseridas no mercado de trabalho local, pois a finalidade da pesquisa foi estudar seus desafios enfrentados no posto de trabalho no setor comercial agropecuário. A escolha das mulheres foi feita com base em informantes-chaves e por indicação, ou seja, uma entrevistada indicava outra conhecida no mercado de trabalho para a pesquisa. No total foram dez mulheres, não como a totalidade do município de Unaí, mas como uma representatividade dessas mulheres que trabalham no setor comercial dos agronegócios na região.

Esse trabalho trata de demonstrar a vida dessas mulheres na regiáo e quais são/foram as barreiras enfrentadas por elas. $\mathrm{Na}$ entrevista semiestruturada, foram formuladas perguntas que seriam básicas para o tema a ser investigado (TRIVINOS, 1987). Segundo Manzini (1990), a entrevista semiestruturada possui um foco em um assunto de interesse e a partir dele elabora-se um roteiro com perguntas principais, complementadas por outras questóes referentes às circunstâncias momentâneas da entrevista. Através desse tipo de entrevista pode surgir informaçóes de forma mais livre e as respostas não estão condicionadas a uma padronização seguida. Portanto, a proposta desse trabalho é o semiestruturado, que consiste na mistura da abordagem estruturada, mas contém a abordagem livre, possibilitando a espontaneidade e improvisação (MANZINI, 1990). Isso serviu para que as entrevistadas se sentissem mais à vontade com os assuntos, expondo seus pontos de vistas pessoais e 
experiências. O roteiro semiestruturado da pesquisa consistiu-se em três blocos: a) perfil da entrevistada; b) perfil socioeconômico da família; c) a mulher no contexto profissional dos agronegócios na regiáo.

Para os registros da pesquisa foram utilizadas as anotaçóes realizadas no roteiro semiestruturado, gravaçóes de áudio e o material digital disponibilizado pelas respondentes via contato de correspondência eletrônica. As análises foram tabuladas por meio de tabelas comparativas, bem como, foram feitos os tratamentos de interpretação de trechos das entrevistas de campo. A seguir, abordam-se os resultados da investigaçáo, os atuais questionamentos e visóes futuras das mulheres que trabalham no setor.

\section{RESULTADOS E DISCUSSÁO}

\subsection{O LUGAR DA MULHER NAS ORGANIZAÇÓES AGROINDUSTRIAIS}

O mercado de trabalho no ramo dos agronegócios é majoritariamente composto pelo sexo masculino. $\mathrm{O}$ fato deste estudo tratar sobre as mulheres que possuem empregos na área e destaque nesse meio, se torna uma forma de inspiração para tantas outras que desejam ingressar no setor agropecuário. Adiante, apresentam-se os principais resultados.

\subsubsection{Perfil das mulheres nas organizaçóes agroindustriais}

A pesquisa apontou que $90 \%$ das mulheres entrevistadas se encontram atualmente solteiras, sendo apenas uma casada. Nesse sentido, a pesquisa demonstrou que, em geral, todas trabalham na regiáo Noroeste do estado de Minas Gerais. A tabela 1 demonstra que são mulheres com idades entre 23 a 34 anos, sendo que algumas relatam ainda não terem planos de se casarem, pois seus objetivos são em relação ao crescimento pessoal. Outras, alegam dificuldades para encontrar parceiros que compreendam o seu modo de vida profissional e salarial. Entre os motivos, as entrevistas salientam que a visão machista ainda persiste, sendo demonstrado de várias formas e em diversos contextos no setor em que trabalham.

Tabela 1 - Perfil das mulheres que atuam nas organizaçôes agroindustriais em Unaí, MG.

\begin{tabular}{l|l|l|l|l|l}
\hline Identificação & Idade & $\begin{array}{l}\text { Estado } \\
\text { Civil }\end{array}$ & Ocupação & Residência & $\begin{array}{l}\text { Local de } \\
\text { trabalho }\end{array}$ \\
\hline Entrevistada 1 & 23 & Solteira & Consultora técnica de vendas & Unaí - MG & Região de Unaí \\
\hline Entrevistada 2 & 29 & Soleira & Coordenadora de adubos & Unaí - MG & Região de Unaí \\
\hline Entrevistada 3 & 24 & Solteira & Assistente técnica de vendas & Unaí - MG & Região de Unaí \\
\hline Entrevistada 4 & 26 & Solteira & Assistente técnica de vendas & Unaí - MG & Região de Unaí \\
\hline Entrevistada 5 & 31 & Solteira & Coordenadora de biológicos & Unaí - MG & Região de Unaí \\
\hline Entrevistada 6 & 26 & Solteira & Assistente técnica de vendas & Unaí - MG & Região de Unaí \\
\hline
\end{tabular}




\begin{tabular}{l|l|l|l|l|l}
\hline Identificação & Idade & $\begin{array}{l}\text { Estado } \\
\text { Civil }\end{array}$ & Ocupação & Residência & $\begin{array}{l}\text { Local de } \\
\text { trabalho }\end{array}$ \\
\hline Entrevistada 7 & 34 & Solteira & $\begin{array}{l}\text { Representante técnica de } \\
\text { vendas }\end{array}$ & Unaí - MG & Região de Unaí \\
\hline Entrevistada 8 & 28 & Casada & Analista técnica comercial & Unaí - MG & Região de Unaí \\
\hline Entrevistada 9 & 27 & Solteira & Promotora de vendas & Unaí - MG & Região de Unaí \\
\hline Entrevistada 10 & 28 & Solteira & Assistente técnica de vendas & Unaí - MG & Região de Unaí \\
\hline
\end{tabular}

Fonte: Pesquisa de Campo (2019).

A entrevistada 7, de 34 anos, ocupa atualmente um cargo de grande importância na empresa em que trabalha, relata ter tido relacionamentos duradouros, mas não o suficiente para resultarem em uma uniáo estável, isso porque haviam adversidades financeiras e de ideias entre os parceiros:

Sempre tive um senso de independência muito grande, por vezes haviam discussōes por diferenças salariais entre eu e eles, simplesmente não aceitavam o fato de que eu ganhava mais que eles. Em situaçóes onde eu queria pagar a conta em algum estabelecimento, se sentiam quase que humilhados (ENTREVISTADA 7).

Esse registro é característico de uma visão patriarcal, onde o sexismo e o machismo são os principais motivos para tal comportamento. Segundo Oliveira e Maio (2016) falar sobre o machismo é algo simples e, ao mesmo tempo complexo, sendo simples porque existem muitos exemplos práticos na sociedade e sendo de fácil identificação principalmente por mulheres; e complexo porque é preciso mais estudos científicos, culturais e políticos para relatar com propriedade, pois se trata de um tema que poucas pessoas conseguem dialogar durante o período de vida, ou seja, pouco se fala nas escolas e pouco se discute na família de forma emancipadora, humanista e respeitosa.

É importante salientar que outras entrevistadas também demonstraram sentir o machismo com relação a envolvimentos pessoais com parceiros, em outro tipo de situação, sobre trabalharem com muitos homens. Tal fato é explicado justamente em virtude de que a área agrícola é marcada pela presença masculina, então quando essas mulheres ingressam nesse meio, há diversas questóes subjetivas no jogo, envolvendo julgamentos sobre a sua competência, juízos de valor aos atributos físicos e questionamentos sobre sua presença no setor. Oliveira (2013) afirma que a posição da mulher no interior de sistemas sociais específicos se verifica com relação às sociedades patrilineares e mesmo patriarcais, ou seja, é marcante o controle da maneira a qual as mulheres devem se comportar, tudo fundamentado pelo sistema patriarcal, de dominação masculina.

Então, certas conquistas profissionais e culturais femininas continuam a provocar reação de surpresa, principalmente em homens. Ao contrário, a ausência de mulheres em posições de representatividade social, não causa nenhum espanto (FRANCO e SANTOS, 2010). Ou seja, uma mulher quando bem-sucedida, causa certo desconforto em seu parceiro, pela sua independência financeira e pelas suas opinióes fortes e presentes. 
Bourdieu (2011) em sua obra diz que os homens entre eles mesmos são produtores de ideais e saberes sobre os sexos, por isso o masculino se ocupa em criar suas próprias regras que tangem o mundo feminino. Beauvoir (1970) constatou uma dominação e opressão masculina posicionada na relação entre o masculino e o feminino, desde suas vestimentas até suas açóes. Diante disso, é possível afirmar que os homens possuem certo tipo de incoerência ao aceitar que suas parceiras estejam em posições que eles estão, seja financeiramente ou em qualquer outro tipo de posição.

A entrevistada 2, de 29 anos, relatou que o seu último relacionamento acabou em virtude de ciúmes, pelo fato do parceiro não admitir que ela trabalhasse com mais homens do que mulheres:

Por diversas vezes ele reclamava do meu relacionamento com os meus colegas de trabalho, bem como com produtores rurais. Nesse meio, principalmente, comercial, o nosso contato com homens é indiscutivelmente em maior número e mesmo me portando como uma profissional da área, o meu ex-parceiro não confiava e não admitia o tipo de profissão que eu tenho (ENTREVISTADA 2).

Essas informações são importantes porque demonstram que além das adversidades enfrentadas diariamente em seus ambientes de trabalho, passam também por dificuldades pessoais em seus relacionamentos, principalmente pela dificuldade de aceitação masculina em relação ao trabalho e as pessoas com quem se relaciona profissionalmente.

Com relação a suas respectivas formações e cargos ocupacionais, as 10 entrevistadas são formadas no curso de Engenharia Agronômica e ocupam cargos com remuneraçóes que variam entre 3 a 15 salários mínimos, onde todas relatam ainda terem acréscimos de comissóes de vendas (Tabela 2).

Tabela 2 - Remunerações das mulheres, idade e ocupação nas organizações rurais em Unaí, MG.

\begin{tabular}{l|l|l|l}
\hline Identificação & Idade & Ocupação & Remuneração \\
\hline Entrevistada 1 & 23 & Consultora técnica de vendas & $\mathrm{R} \$ 3500+$ comissóes \\
\hline Entrevistada 2 & 29 & Coordenadora de adubos & $\mathrm{R} \$ 7000+$ comissóes \\
\hline Entrevistada 3 & 24 & Assistente técnica de vendas & $\mathrm{R} \$ 3500+$ comissóes \\
\hline Entrevistada 4 & 26 & Assistente técnica de vendas & $\mathrm{R} \$ 3500+$ comissóes \\
\hline Entrevistada 5 & 31 & Coordenadora de biológicos & $\mathrm{R} \$ 7000+$ comissóes \\
\hline Entrevistada 6 & 26 & Assistente técnica a campo & $\mathrm{R} \$ 5800+$ comissóes \\
\hline Entrevistada 7 & 34 & Representante técnica de vendas & $\mathrm{R} \$ 15000+$ comissóes \\
\hline Entrevistada 8 & 28 & Analista técnica comercial & $\mathrm{R} \$ 4000+$ comissóes \\
\hline Entrevistada 9 & 27 & Promotora de vendas & $\mathrm{R} \$ 3500+$ comissóes \\
\hline Entrevistada 10 & 28 & Assistente técnica de vendas & $\mathrm{R} \$ 3500+$ comissóes \\
\hline
\end{tabular}

Fonte: Pesquisa de Campo (2019). 
Através da tabela 2 é possível verificar a existência de uma tipologia entre as mulheres com relação aos seus cargos ocupacionais e salários nas empresas. Para tanto, define-se em três grandes blocos, sem adicionar comissóes: a) profissionais de cargos iniciais em empresas dos agronegócios: são mulheres que estão em estágio inicial nas empresas, recebendo uma remuneração entre $\mathrm{R} \$ 3.000$ a $\mathrm{R} \$ 4.000$, sendo possível identificar uma remuneração de cargos e salários de acordo com os padróes iniciais da carreira estabelecidos pelo setor privado; b) profissionais de cargos intermediários em empresas dos agronegócios: são profissionais que estão em fase de crescimento com salários que variam de $\mathrm{R} \$ 5.000 \mathrm{a}$ $\mathrm{R} \$ 10.000$, com possibilidade de almejar ascensão profissional na estrutura do plano de carreira; c) profissionais consolidadas em empresas dos agronegócios: são aquelas mulheres que recebem acima de $\mathrm{R} \$ 10.000$ e que se encontram nessas empresas por um maior período de tempo, sendo que alcançaram altos cargos gerenciais.

É possível verificar que existem algumas empresas que estão priorizando mulheres. Conforme Probst (2003), a mulher quando ingressa na empresa, em áreas estratégicas que envolvem alto conhecimento, ela tem cada vez mais importância estratégica, pois trabalha naturalmente com a diversidade e processos multifuncionais. A sensibilidade feminina, por exemplo, permite a constituição de equipes de trabalho marcadas pela diferença e pela heterogeneidade. Segundo ela, equipes desse tipo, quando atuam de forma sinérgica, fazem emergir soluçóes variadas e criativas para problemas aparentemente insolúveis. A empresa que aposta na singularidade de seus interlocutores internos se torna mais inteligente, mais capaz e mais ágil.

Esta pesquisa demonstra que ocupando cargos comerciais as mulheres da região se destacam no mercado de trabalho. Além disso, estão cada vez mais em busca de conhecimento técnico em suas respectivas áreas, com potencial de qualificação e disputa pelos melhores postos de trabalhos.

Há uma linha argumentativa que focaliza em priorizar o âmbito feminino para o avanço, principalmente, mais ético dos agronegócios. Atualmente, é assunto de debate em questóes acadêmicas e ainda mais no meio coorporativo-privado. A entrevistada 7, em virtude de sua maior experiência profissional, atualmente, participa das contrataçóes da empresa e diz priorizar por mulheres:

Atualmente, dou oportunidade outras mulheres, não por questôes do sexo feminino, mas sim por saber que são capazes de chegar até onde cheguei e até mais, se eu confiei em mim, eu confio nelas. Sempre tenho bons resultados, pois somos cuidadosas, temos força e muita dedicação em nossos objetivos, independentemente do gênero sexual (ENTREVISTADA 7).

O relato descreve questóes semelhantes ao que Probst (2003) trata, ou seja, o mundo está apostando nos valores femininos por essas mulheres possuírem alta competência e apostam no trabalho em grupo em vez do individualismo, a persuasão em oposição ao autoritarismo, a cooperação no lugar de competição. Nesse processo de conquistas, Probst (2003) argumenta que as mulheres que mais se destacam são justamente aquelas que não fazem da condição feminina a sua base, já que nenhuma mulher se tornou astronauta, juíza da Suprema Corte, presidente de uma corporação, gerente comercial, grande professora 
com mestrado e doutorado, apenas por não ser homem. Ou seja, não estão nesses cargos por necessidade das instituiçóes de diversificar o seu quadro, mas subiram por seus méritos e esforços, medidos por padróes que valem para ambos os sexos.

Nesse contexto, é importante demonstrar o perfil socioeconômico das entrevistadas, bem como de suas respectivas famílias. Assim, é possível analisar a condição das mulheres da pesquisa, bem como, as questôes estruturais presentes nesse debate.

\subsection{PERFIL SOCIOECONÔMICO DA FAMÍLIA DAS ENTREVISTADAS}

Essa seção, na pesquisa, é importante para conhecer as raízes históricas dessas mulheres em virtude de que, em sua grande maioria, a situação da família possui influência e, na maioria das vezes, a condição familiar, mesmo não sendo pela profissão que optaram seguir, são formadoras de elementos como o caráter, a força de vontade e virtudes, ou seja, há relaçôes de capital cultural fortemente relacionadas com suas famílias.

Todas as entrevistadas nessa pesquisa têm origem de famílias brasileiras, sendo que algumas com ligação rural, outras urbanas, como demostra a tabela 3 a seguir. Foi notório na investigação que todas as famílias, em sua grande maioria, são de classe baixa, e algumas famílias de classe média. A classificação da classe familiar baseou-se na opiniáo própria de cada entrevistada.

Tabela 3 - Perfil socioeconômico de mulheres que atuam nas organizaçóes agroindustriais em Unaí, MG.

\begin{tabular}{l|l|c|c|c}
\hline Identificação & Idade & Origem familiar & Classe familiar & Influência \\
\hline Entrevistada 1 & 23 & Urbana & Média & Pais \\
\hline Entrevistada 2 & 29 & Rural & Baixa & Pais \\
\hline Entrevistada 3 & 24 & Urbana & Baixa & Pais \\
\hline Entrevistada 4 & 26 & Rural & Baixa & Irmã \\
\hline Entrevistada 5 & 31 & Rural & Baixa & Pais \\
\hline Entrevistada 6 & 26 & Urbana & Média & Pais \\
\hline Entrevistada 7 & 34 & Urbana & Média & Pais \\
\hline Entrevistada 8 & 28 & Rural & Baixa & Pais \\
\hline Entrevistada 9 & 27 & Rural & Baixa & Irmãos \\
\hline Entrevistada 10 & 28 & Rural & Baixa & Pais \\
\hline
\end{tabular}

Fonte: Pesquisa de Campo (2019).

O curso de Agronomia, atualmente, segundo o Mundo Vestibular (2020) gira em torno de $\mathrm{R} \$ 600$ a $\mathrm{R} \$ 2000$, valores nos quais se tratando de uma família de baixa renda seriam elevados. Nesse contexto, as mulheres entrevistadas foram estimuladas a procurar meios de contribuir com as suas respectivas famílias, mesmo aquelas de renda média. Além disso, através de dedicação e esforço, buscam em todo momento alcançar seus projetos de vida. 
Portanto, não é apenas a condição financeira que está em jogo, pois diferentemente dos homens que, simplesmente, escolhem uma profissão ou especialidade que lhes agrade ou convenha, as mulheres mesmo quando mais capazes têm inúmeros obstáculos a vencer. A educação das mulheres em algumas famílias, ainda favorece a baixa autoestima, a insegurança intelectual, a dependência emocional e financeira (FRANCO e SANTOS, 2010). Diante disso, é importante o apoio emocional que as entrevistadas possuem de suas famílias, independente do fator renda, mesmo porque os cursos de ciências agrárias estão imersos em um mundo recheado de preconceitos, em alguns casos, até dentro de suas próprias casas.

As entrevistadas, que possuem origem rural, na maioria das vezes, não possuem famílias como donas de propriedades rurais, mas cresceram nesse meio, sejam em vilarejos ou cidades pequenas com plantaçóes ao redor, visitando fazendas onde os pais trabalhavam. A entrevistada 2 diz que sua família é de baixa renda, mas que se inspirou em seu pai:

\begin{abstract}
Meu pai nunca teve uma propriedade rural, mas sempre trabalhou nesse meio. Ele quem me levava para o seu trabalho e lá ele realizava processos desde o plantio até a colheita de grãos, isso me encantava. Meus pais nunca tiveram condiçôes de pagar uma faculdade para eu e minha irmã. Meu pai sempre batalhou para manter a nossa família e a minha mãe mesmo sendo uma dona de casa, sempre nos incentivou a lutarmos pelos nossos sonhos. Era o sonho do meu pai ter duas filhas agrônomas. Isso está se realizando, me formei em faculdade particular, mas com bolsa 100\% ProUni. Minha irmã já possui uma formação em Ciências Agrárias e, atualmente, está terminando a sua graduação em Agronomia, em uma faculdade federal. É um grande orgulho para os meus pais, que tanto lutaram para verem suas duas filhas formadas, e também para mim, por ter conseguido chegar onde eu queria e saber que ela também irá chegar (ENTREVISTADA 2).
\end{abstract}

Isso demonstra que, mesmo com família de baixa renda e configuração patriarcal, onde o pai é o responsável pelos ofícios que tragam renda para manter a família e a mãe pela casa e filhas, eles ampliaram suas percepções de mundo possibilitando que essa configuração possa ser diferente quando suas filhas forem mães ou optem por não ter filhos. Tal afirmação se justifica em virtude de que o sonho do pai em querer que suas filhas ingressem em uma profissão de predominância masculina mostra que há uma intenção de quebrar as estruturas da dominação masculina e, de certa forma, o protagonismo do pai fortalece o empenho em reduzir essa diferença, uma vez que se fosse em épocas passadas, as filhas seriam destinadas a se casarem e terem a mesma posição de inferioridade em relação ao âmbito profissional. Porém, elas podem ser também futuras mães, esposas, donas de casa, mas com seus objetivos profissionais alcançados.

Simóes e Hashimoto (2012) dizem que além da maternidade, a mulher atual passa a se preocupar também com a sua satisfação pessoal e o sucesso de sua carreira profissional, onde busca, por exemplo, aperfeiçoar-se por meio de estudos, garantindo assim a sua ascensão no mercado de trabalho. Assim, a entrada da mulher no mercado de trabalho traz repercussões na organização e na estrutura familiar, configurando novas formas e arranjos familiares.

São diversas as situaçóes em que, as entrevistadas de família com classe de renda baixa, expressam terem passado por grandes desafios e se espelhado em conselhos familiares. 
Algumas deixam nítido que somente estão onde já chegaram por muito esforço e dedicação, em função que as respectivas famílias não tinham condiçôes de mantê-las. A entrevistada 9 , por exemplo, relata que teve muitas dificuldades, inclusive, pela condiçáo de ser a primeira de sua família a estudar em busca de melhores condiçóes de vida:

Sou a primeira da minha família a ter uma graduação, não tive muito apoio financeiro, visto que as condiçóes econômicas da minha família não permitiam. Quando estudava, a minha situação era precária, sempre estudei com auxílio de bolsas e procurava desenvolver outras atividades como fonte de remuneraçáo, como venda de doces, fazer maquiagens, unhas e trabalhos acadêmicos, hoje, já vejo que cada esforço está valendo a pena (ENTREVISTADA 9).

A baixa renda pode ser um fator de motivação e de rompimento de barreiras. Leone, Maia e Baltar (2010) afirmam que para compreender a dinâmica da renda e dos indicadores de pobreza no Brasil, é preciso analisar as mudanças que estáo acontecendo nos arranjos familiares, associadas a transformaçóes demográficas e cultural. No que tange as transformaçóes demográficas, destaca-se a diminuição da fecundidade, por exemplo. No quesito social e cultural, verifica-se o menor número de matrimônios, aumento das separaçóes e atrasos das unióes, definindo assim um novo papel da mulher na família e no trabalho.

Se todas essas mulheres que emergiram de classe baixa tiveram que se esforçar financeiramente por falta de condiçóes, por outro lado, as três entrevistadas de família de classe média e de origem urbana, precisaram de muita dedicação para ocupar sua posiçáo atual. Elas possuem pais com formaçóes, porém, em áreas diferentes da agricultura ou pecuária. A entrevistada 1, quando indagada sobre sua influência, afirma que a motivação para ingresso na área envolve a soberania alimentar, ou seja, que seu trabalho pode contribuir para a alimentação mundial e que mesmo possuindo pais formados e empregados, também precisou passar por superaçóes:

Minha mãe é contadora e o meu pai enfermeiro, apesar disso, estudei em faculdade pública e tinham inúmeros outros gastos para poder me manter em Brasília (moradia, alimentação, etc), meus pais me incentivavam sempre a correr atrás do meu sonho. Portanto, durante o período acadêmico sempre fiz estágios e, além disso, trabalhava com vendas (roupas, bolsas e acessórios) para ajudar nas finanças. $\mathrm{O}$ meu apreço pela área agronômica surgiu ao assistir Globo Rural pela manhã, ao ver extensas plantaçóes pelas estradas, eu queria de alguma forma participar daquilo (ENTREVISTADA 1).

Tal depoimento ressalta que mulheres, independentemente de suas classes sociais, possuem a habilidade e força para conseguirem o que objetivam. Não muito diferente da entrevistada 1, a entrevistada 7 também passava por situaçóes parecidas, pois embora os pais tivessem bons empregos, sempre foi incentivada a ir atrás de seus sonhos.

Não posso afirmar que passei necessidade. Meus pais são servidores públicos, estudei em faculdade particular, mas tive que trabalhar para ajudar nas finanças. Trabalhei em lojas de roupas e sapatos, tinha o meu dinheiro, mesmo que pouco, para contribuir com os meus pais (ENTREVISTADA 7). 
$\mathrm{O}$ fato em comum entre essas mulheres, de renda baixa ou não, além de ser seus propósitos de vida, eram os trabalhos secundários que realizavam. A venda de roupas, calçados, maquiagens, trabalhos em estética, demonstram que essas mulheres são sobretudo, femininas. Adiante, o trabalho apresenta as experiências das mulheres no âmbito das organizaçôes com foco no setor agropecuário de Unaí, MG.

\subsection{A MULHER NA IMERSÃO DO MUNDO PROFISSIONAL NO COMPLEXO AGROINDUSTRIAL LOCAL}

O primeiro emprego, tanto das recém-formadas, quanto aquelas que já possuem anos de experiência nesse mercado, envolveu, por unanimidade, algum tipo de dificuldade no início para encontrar o primeiro emprego. Algumas, sentiram o preconceito em virtude da sua condição de mulher, outras pelo nível de experiência requerido pelas empresas. Em relaçáo tempo de carência do final da faculdade até ingressar no mercado de trabalho, variou entre um mês a seis anos.

Tabela 4 - Tempo de carência e dificuldades do primeiro emprego das mulheres que atuam nas organizaçôes agroindustriais em Unaí, MG.

\begin{tabular}{l|c|c|c|c}
\hline Identificação & Idade & Tempo de carência & $\begin{array}{c}\text { Dificuldades por } \\
\text { questôes de gênero }\end{array}$ & $\begin{array}{c}\text { Dificuldades por nível de } \\
\text { experiência }\end{array}$ \\
\hline Entrevistada 1 & 23 & 5 meses & Sim & Sim \\
\hline Entrevistada 2 & 29 & 1 ano & Sim & Sim \\
\hline Entrevistada 3 & 24 & 6 meses & Sim & Sim \\
\hline Entrevistada 4 & 26 & 1 ano & Não & Não \\
\hline Entrevistada 5 & 31 & 1 mês & Não & Sim \\
\hline Entrevistada 6 & 26 & 1 ano & Não & Sim \\
\hline Entrevistada 7 & 34 & 6 anos & Sim & Sim \\
\hline Entrevistada 8 & 28 & 4 meses & Sim & Não \\
\hline Entrevistada 9 & 27 & 1 mês & Sim & Sim \\
\hline $\begin{array}{l}\text { Entrevistada } \\
10\end{array}$ & 28 & 2 meses & & \\
\hline
\end{tabular}

Fonte: Pesquisa de Campo (2019).

Das dez entrevistadas, três relataram que não sentiram preconceito pela condição de mulheres quando estavam à procura de emprego, mas por falta de experiência. Porém, a entrevistada 6 relata que, em uma entrevista de trabalho, passou por uma situação que talvez pudesse ser duvidosa:

Estava eu e mais dois homens na entrevista para o trabalho em uma empresa, um deles, em conversa relatou que não tinha experiência. Após um tempo, não fui selecionada, e a informação na qual recebi seria por falta de experiência que a empresa buscava, porém, esse mesmo rapaz que me disse não ter experiência, foi contratado. Não posso afirmar com total 
certeza que tenha sido por eu ser uma mulher, talvez, ele tenha se saído melhor do que eu na entrevista, mas, fiquei com minhas dúvidas (ENTREVISTADA 6).

Gomes (2010) afirma que o preconceito contra as mulheres está contida no mascaramento e na subordinação em nossa linguagem cotidiana, ou seja, se encontra em uso de expressóes e de diversos jogos de linguagem, em palavras com duplo sentido, na criação de preferenciais ou referenciais para dar conta de uma realidade que não é a mais condizente com o seu papel na sociedade, também na criação de estereótipos que moldam formas singulares de preconceitos.

Diante disso, é possível predizer que em algumas situações, mulheres não se dão conta de que estâo passando por algum tipo de preconceito, pois também já internalizaram estas situaçóes. Na maioria das vezes, ele se apresenta de forma disfarçada com outras justificativas, e, portanto, não percebem. Porém, vale ressaltar que isso não é uma generalização. Por exemplo, a entrevistada 4 destacou que náo foi contratada em uma vaga de emprego, por questôes de experiência e não de gênero sexual, já que a outra candidata possuía experiência:

Já concorri em vagas com homens e com mulheres. Numa ocasiáo em questão, a outra candidata possuía um nível de experiência a mais que eu. Compreendi totalmente o requisito de classificação, a parabenizei e segui em frente (ENTREVISTADA 4).

Tal situação está relacionado com a falta de oportunidades para recém-formados, independente de gênero. Isso porque algumas empresas sentem uma necessidade em confiar seus cargos a pessoas já experientes, com a justificativa de evitarem possíveis problemas internos posteriores. Melo e Borges (2007) afirmam que a geração de empregos no país poderia contemplar pessoas no sentido de garantir a experiência do primeiro emprego após o término de suas formaçóes, pelo incentivo de programas para a inserção profissional, sendo desenvolvido pelas organizaçóes. São questôes complexas já que as empresas são em sua maioria privadas.

A entrevistada 5 sempre teve experiência no ramo, uma vez que se formou com o título de Técnica Agrícola antes de ingressar no curso de Agronomia, portanto, relatou não sentir preconceito ou outro tipo de dificuldade:

\footnotetext{
Por já ser formada como técnica agrícola, através dos estágios fiz boas amizades que me ajudaram durante e após a minha formação em Agronomia, meio que já saí empregada. Não senti preconceito com relação ao trabalho, mas sim durante a graduação. Isso porque alguns colegas duvidavam da minha capacidade por ser mulher (ENTREVISTADA 5).
}

Sentir preconceito durante a graduação é algo comum enfrentado entre mulheres. Nos cursos das ciências agrárias há uma maior possibilidade, pois são cursos advindos de uma área compostas em sua grande maioria por homens. Ingressar nessa área se torna um desafio por desconfiarem de suas capacidades em relaçâo as questóes teóricas e, principalmente, práticas.

A entrevistada 9 relatou sentir bastante preconceito durante sua graduação. Muitas vezes, de caráter prático: 
Duvidavam de mim e de minhas colegas em questôes de fertilidade do solo, uso de defensivos agrícolas e implementos ou máquinas agrícolas, e já cheguei a escutar perguntas do tipo 'você sabe do que está falando?'. Soltavam piadinhas durante as aulas práticas, onde diziam que não conseguiríamos ficar por muito tempo debaixo do sol quente, que iríamos suar nossos cabelos ou que iriamos quebrar nossas unhas ao manusear máquinas e implementos agrícolas (ENTREVISTADA 9).

Alguns questionamentos podem e devem ser levantados a partir de situaçôes de preconceito na área agrícola: a) por que os homens classificam o meio rural como algo tão másculo? As respostas são múltiplas, mas principalmente pela configuração antiga de que quem atuava nessa área eram eles, por se classificarem como mais fortes e resistentes ao trabalho braçal do meio rural, conceito que já está sendo mudado em virtude do avanço das tecnologias no campo; b) por que possuem uma visão de que a mulher para atuar nesse meio não pode ser feminina ao mesmo tempo? Talvez, por possuírem a visão de que uma mulher que cuida de sua aparência não pode estar atuando no campo de tal forma, por acharem que as duas coisas não combinam, o que já não condiz também com a realidade. $\mathrm{A}$ entrevistada 8 expressou a sua opiniáo:

A vaidade de uma mulher não estima a sua capacidade profissional. Uma mulher pode trabalhar no campo com suas unhas feitas, seus cabelos arrumados e um batom em suas bocas sim. O que irá diferenciá-la naquele momento será a sua capacidade de realizar o seu trabalho. Nós somos mulheres e femininas, não devemos esquecer a nossa feminilidade, em nenhuma situação, isso faz parte de nós e se torna inclusive o nosso diferencial (ENTREVISTADA 8).

O maior tempo de procura pelo primeiro emprego partiu da entrevistada que entre as dez, hoje se destaca por ter o maior salário. Um fato curioso, e de grande superação, onde ela relata ter passado por tempos mais difíceis que atualmente, por ser mulher:

Fiquei seis anos à procura de um emprego, pois me formei em 2012 e na época eu morava em Brasília, onde quase não havia área de atuação, também era pelo fato de eu ser nova, mulher, sem experiência. Era frustrante a cada não que eu levava, principalmente por saber que era por eu ser mulher. Por fim, estive quase desistindo de seguir na área em que me formei, até que na última tentativa que eu prometi a mim, a oportunidade me foi dada. Dentro da empresa eu me doei por inteira, hoje sou grata, tudo isso me fez chegar onde estou agora (ENTREVISTADA 7).

Em função da época de formação da entrevistada 7, de fato, é possível afirmar que eram condições mais difíceis. As entrevistadas também responderam com relação à confiança em si mesmas e por parte dos produtores rurais. Entre elas, quatro demonstraram ainda não sentirem total confiança pessoal, algumas pela inserção recente no mercado de trabalho comercial, outras por sentirem dificuldades que estão superando aos poucos. Com relaçáo aos produtores, mesmo aquelas que confiam em si mesmas, relataram não sentir a confiança total vinda de produtores. Do total das entrevistadas, todas afirmaram não sentirem confiança o suficiente. 
Tabela 5 - Fator confiança das mulheres que atuam nas organizaçóes agroindustriais em Unaí, MG.

\begin{tabular}{l|l|c|c}
\hline Identificação & Idade & Confiança em si mesma & Confiança por parte de produtores rurais \\
\hline Entrevistada 1 & 23 & Não totalmente & Não \\
\hline Entrevistada 2 & 29 & Sim & Não \\
\hline Entrevistada 3 & 24 & Não totalmente & Não \\
\hline Entrevistada 4 & 26 & Sim & Não \\
\hline Entrevistada 5 & 31 & Sim & Não \\
\hline Entrevistada 6 & 26 & Sim & Não \\
\hline Entrevistada 7 & 34 & Sim & Não \\
\hline Entrevistada 8 & 28 & Sim & Não \\
\hline Entrevistada 9 & 27 & Não totalmente & Não \\
\hline Entrevistada 10 & 28 & Não totalmente & Não \\
\hline
\end{tabular}

Fonte: Pesquisa de Campo (2019).

Durante o ingresso no mercado de trabalho há certa normalidade nas questóes sobre inseguranças pessoais, pois os desafios são grandes, às vezes, com pouca experiência e incertezas. O mercado de trabalho, crescentemente, requer maior densidade de conhecimentos especializados e multidisciplinares para atuar na área e, além disso, o convívio com colegas de trabalho proporciona um ambiente de troca de informaçóes e o fator confiança pessoal é adquirido com o tempo nas relaçóes profissionais dentro e fora da empresa.

As mulheres que demonstraram confiança pessoal têm maior experiência no campo e na área comercial. A confiança, com relação aos produtores não ser efetiva, atribui-se ao fato de que são produtores com diversos tipos de pensamentos, formas de criação e cultura. A entrevistada 2 comenta como é chegar para o trabalho em propriedades rurais todos os dias:

Não é sempre que somos bem recebidas e se engana quem acha que sim. Há muitos produtores que confiam em nossos serviços, mas também há aqueles de pé atrás. Talvez por sermos mulheres, ou talvez, por já terem passado por situaçóes ruins com comerciantes da área com relação aos produtos, é muito relativo. Então, o negócio é chegar e mostrar trabalho (ENTREVISTADA 2).

Todas as entrevistadas responderam de forma similar, embora ainda tenham produtores com a visão patriarcal de que as mulheres são responsáveis pelas tarefas do ambiente doméstico, sendo que, atualmente, ocorreram vários avanços em relação aos preconceitos sociais com as mulheres. No que tange ao fato de considerar que esse mercado de trabalho no campo dos agronegócios tem maiores barreiras e entraves para mulheres, todas também forneceram respostas similares, como a da entrevistada 10 :

Mais difícil não, desafiador eu diria. Somos mulheres, carregamos em nosso sangue a capacidade de superar qualquer coisa ou desafio, seja em qual profissão for. O mercado está 
se abrindo para nós e estamos vindo com tudo para mostrar a nossa capacidade. Iremos superar tudo, inclusive o preconceito (ENTREVISTADA 10).

Quando indagadas sobre as perspectivas pessoais, a principal resposta envolve o desafio enfrentado por elas em mudar a visão mundial de que mulheres são minoria nessas áreas, e para isso, passando por superaçóes pessoais e demonstração de suas capacidades. Crescentemente é possível constatar notícias sobre o crescimento de mulheres na área e, em tantas outras, incluindo náo somente o âmbito comercial, mas como as mulheres produtoras rurais, bem como grandes pesquisadoras e professoras em Instituiçóes de Ensino Superior. A entrevistada 3 comenta como visualiza o futuro para as mulheres no mercado de trabalho:

Aos poucos já estamos por toda parte, em todas as profissóes e mudando o antigo conviver familiar. Somos mães, donas do lar, profissionais, namoradas, esposas, e isso nos torna o diferencial. O mundo precisa do diferencial (ENTREVISTADA 3).

Nesse sentido, é possível anotar nesta pesquisa vários avanços para as mulheres no campo de trabalho do setor agropecuário. No entanto, é preciso ponderar que, conforme Redin (2015), é ingênuo deixar de lado o fato de que a mulher rural náo ganhou e vem ganhando espaço na sociedade e na própria família, com suas lutas diárias, reinvindicaçóes e, sendo mais ousado, dizer que a mulher é autônoma, independente e vigia-se de qualquer ato de dominação masculina, seja como representação social ou pela sua prática em sociedade.

Aos poucos, a mulher está adquirindo o seu potencial de se igualar com relação entre os sexos e ascender na relação da configuração familiar. Nessa pesquisa, com um lócus de estudo pontual, consegue-se apresentar um seleto grupo de mulheres que tiveram êxito pessoal em seus empreendimentos pessoais. No entanto, a luta social pela inserção, reconhecimento e valorização das mulheres no mercado de trabalho continua sendo objeto de pesquisa e avanços sociais, em especial, no campo dos agronegócios.

\section{CONSIDERAÇÓES FINAIS}

A pesquisa objetivou analisar as mulheres inseridas em organizaçóes que trabalham com os agronegócios na região de Unaí, Minas Gerais. Nessa investigação foi possível identificar que a mulher está ganhando espaço em um mercado de trabalho extremamente masculinizado. Logo, o título que apresenta a menção: "lugar de mulher é onde ela quiser" um dito popular entre as mulheres que lutam pelo seu espaço, configurando-se como uma provocação com objetivo de chamar a atenção das mulheres para esse trabalho. Isso porque os resultados obtidos foram importantes tanto para servirem de inspiração para as mulheres, quanto para informá-las sobre o mercado de trabalho para mulheres nos agronegócios em Unaí, Minas Gerais.

As mulheres que trabalham em organizaçóes agroindustriais relacionadas aos agronegócios são, majoritariamente, solteiras, jovens, provenientes de famílias de baixa renda, relativamente novas em seus cargos, possuindo um padrão salarial razoável e determinado pelo tempo de trabalho na empresa. Nesta investigação foi possível identificar três tipologias de mulheres no mercado de trabalho de empresas dos agronegócios: a) profissionais de 
cargos iniciais em empresas dos agronegócios; b) profissionais de cargos intermediários em empresas dos agronegócios; c) profissionais consolidadas em empresas dos agronegócios.

A pesquisa identificou que todas as mulheres foram influenciadas, de certa forma, pelos membros da família para a formação e trabalho no mercado dos agronegócios. $\mathrm{O}$ tempo de ingresso no mercado de trabalho variou entre um mês a seis anos após formadas, sendo que algumas relataram problemas relacionados a questáo de gênero e a maioria afirmou que há dificuldades em virtude da falta de experiência no momento do processo de recrutamento e seleção. As respostas em relação a questão da confiança no seu potencial apresentaram-se divididas, no entanto, todas sustentaram que não há confiança por parte dos produtores rurais, alternando respostas em relação aos preconceitos de gênero, a desconfiança em relação ao produto ou sobre a condição de vendedoras.

Diante dos resultados, o perfil das mulheres entrevistadas é muito diferente do perfil patriarcal do passado. Atualmente, as mulheres possuem maior autonomia, alcançam postos de trabalho e cargos de alta responsabilidade tanto quanto os homens ocupam, sendo que, ao mesmo tempo, ainda realizam os ofícios tradicionais e culturais no âmbito do lar e da sociedade. Trabalhar fora de casa com a possibilidade de não depender exclusivamente dos homens é uma conquista ainda recente entre as mulheres. Essa pesquisa mostrou que a independência pessoal e financeira é resultado de todo o seu esforço durante a busca pela sua formação, sendo motivo de orgulho para todas e para seus familiares. Demonstrou também que hoje, as mulheres já têm a confiança, inclusive, de seus pais para saírem de casa em busca de seus próprios sonhos, demonstrando que a configuração e o pensamento das famílias estão em processo de metamorfose.

A investigação demostrou que ainda existem preconceitos em relação ao trabalho feminino, principalmente na área dos agronegócios, porém, diante de várias superações, estão conseguindo o seu espaço, em busca de respeito, aliado ao uso de estratégias de incessante preocupação com o conhecimento, a educação, sua feminilidade e o profissionalismo. Mesmo que, de forma lenta, esse processo é progressivo e constante. A pesquisa demonstrou situaçóes desafiadoras em que as entrevistadas enfrentam no mercado de trabalho nos agronegócios, visto que as mulheres possuem capacidades iguais no âmbito profissional, sendo que esse fenômeno provoca mudanças profundas em fatos históricos sobre a inserção da mulher no mercado de trabalho. Há uma necessidade contínua de promover incentivos às outras mulheres que possuem projetos de vida similares, através de promoção de políticas públicas e ações informativas, com a cooperação do setor privado no intuito de demonstrar cada vez mais a visibilidade feminina no mundo do mercado de trabalho dos agronegócios.

\section{REFERÊNCIAS}

ARAÚJO, V. F.; RIBEIRO, E. P. Diferenciais de salários por gênero no Brasil: uma análise regional. CAPs, CNPq, p.1-22, 2001. Disponível em: https://www.ufrgs.br/ppge/ wp-content/themes/PPGE/page/textos-para-discussao/pcientifica/2001_11.pdf. Acesso em: 12 nov. 2019. 
BARROS, G. S. C. et al. Mulheres no agronegócio. Centro de Estudos Avançados em Economia Aplicada (Cepea), Piracicaba, v.1, n.3, 2019.

BARROS, G. S. C. et al. Mulheres no agronegócio. Centro de Estudos Avançados em Economia Aplicada (Cepea), Piracicaba, v.1, n.3, nov. 2018.

BAYLÃO, A. L. S.; SCHETTINO, E. M. O. A inserção da mulher no mercado de trabalho brasileiro. In: SIMPÓSIO DE EXCELÊNCIA EM GESTÁO E TECNOLOGIA, XI., AEDB, Anais [...]. Rio de Janeiro, 2014. Disponível em: https:// www.aedb.br/seget/arquivos/artigos14/20320175.pdf. Acesso em: 12 nov. 2019.

BEAUVOIR, S. O segundo sexo I: fatos e mitos. São Paulo: Difusão europeia do livro. 1970.

BOURDIEU, P. A dominação masculina. 10. ed. Tradução de Maria Helena Kuhner. Rio de Janeiro: Bertrand Brasil, 2011.

BRUSCHINI, C. Trabalho feminino no Brasil: novas conquistas ou persistência na discriminação? In: MEETING OF THE LATIN AMERICAN STUDIES ASSOCIATION, 19., Anais [...]. Chicago, 1998. 32p. Disponível em: http://biblioteca. clacso.edu.ar/ar/libros/lasa98/Bruschini.pdf. Acesso em: 19 dez. 2019.

CAMPOS, R. A. Executivas e líderes. In: CORDEIRO, A.; BIFF, M.; PAFFARO, R.; FIGUEIRÊDO, T. (ORGs). Mulheres do agro. Belo Horizonte: Editora Letramento, 2019.p.136-140.

CARREIRA, D.; AJAMIL, M.; MOREIRA, T. (ORGS.). Liderança Feminina no século 21. São Paulo: Cortez; Rede Mulher de Educação, 2001.

CARRIJO, M. C.; FERREIRA, S. R. R. Empreendedorismo feminino no brasil: uma análise a partir de dados do global entrepreneurship monitor (GEM).

Empreendedorismo, Gestão e Negócios, v. 6, n. 6, p. 200-22, mar. 2017.

CEPEA - CENTRO DE ESTUDOS AVANÇADOS EM ECONOMIA APLICADA. Participação feminina do agro é impulsionada por mulher com mais de 30 anos e maior qualificação. CEPEA, USP, ESALQ, 2019. Disponível em: https://www.cepea. esalq.usp.br/br/releases/cepea-participacao-feminina-no-agro-e-impulsionada-por-mulhercom-mais-de-30-anos-e-maior-qualificacao.aspx. Acesso em: 2 dez 2019.

CORDEIRO, A.; BIFF, M.; PAFFARO, R.; FIGUEIRÊDO, T. (ORGs). Mulheres do agro: inspiraçóes para vencer desafios dentro e fora da porteira. Belo Horizonte: Editora Letramento, 2019.

FIGUEIREDO, Z. N. et al. Interação de alunas bolsistas do ensino médio com o curso de Agronomia no projeto agro mulher. Relva, Juara, v. 3, n. 2, p. 144-157, jul./dez. 2016. 
FRANCO, T.; SANTOS, E. G. Mulheres e cirurgiãs. Revista do Colégio Brasileiro de Cirurgióes, Rio de Janeiro, v. 37, n. 1, p. 72-77, jan./fev. 2010.

GOMES, S. S. Preconceito e discriminação: as bases da violência contra a mulher. Psicologia: Ciência e Profissão, Brasília, v. 30, n. 3, p. 556-57, set. 2010.

JONATHAN, E. G. Mulheres empreendedoras: medos, conquistas e qualidade de vida. Psicologia em Estudo, Maringá, v. 10, n. 3, p. 373-382, set./dez. 2005.

KARPINSKI, B. A atuação das mulheres se consolida no agronegócio no Brasil. 2017. Disponível em: https:/gauchazh.clicrbs.com.br/economia/campo-e-lavoura/ noticia/2016/11/atuacao-das-mulheres-se-consolidano-agronegocio-no-brasil-8485766. html. Acesso em: 1 dez 2019.

LAVINAS, L.; LÉON, F. Emprego feminino no Brasil: mudanças institucionais e novas inserçôes no mercado de trabalho. CEPAL, Santiago de Chile, v.2, n.60, p.1-85, set. 2002.

LEONE, E. T.; MAIA, A. G.; BALTAR, P. E. Mudanças na composição das famílias e impactos sobre a redução da pobreza no Brasil. Economia e Sociedade, Campinas, v. 19, n. 1, p. 59-77, abr. 2010.

MACHADO, H. V. Identidade empreendedora de mulheres no Paraná. 2002. 192 f. Tese (Doutorado em Engenharia de Produção) - Programa de Pós-Graduação em Engenharia de Produção, Universidade Federal de Santa Catarina, Florianópolis, 2002.

MANZINI, E. J. A entrevista na pesquisa social. Didática, São Paulo, v. 26/27, p. 149158, 1990.

MELO, S. L.; BORGES, L. O. A transição da universidade ao mercado de trabalho na ótica do jovem. Psicologia: ciência e profissáo, Brasília, v.27, n.3, p. 376-395, 2007.

MUNDO VESTIBULAR. Quanto custa estudar Agronomia. 2020. Disponível: https:// www.mundovestibular.com.br/cursos/quanto-custa-estudar-agronomia. Acesso em: 21 jan. 2020.

OLIVEIRA, L. M. Metendo a real: machismo, misoginia e violência contra as mulheres no site de rede social facebook. 102 f. (Monografia) - Curso de Serviço Social, Universidade Federal do Rio Grande do Norte. 2013.

OLIVEIRA, M.; MAIO, E. R. Você tentou fechar as pernas?” - a cultura machista impregnada nas práticas sociais. Polêmica, v.16, n.3, p.1-18, jul./set. 2016.

PORTAL CORTEVA AGRISCIENCE. Mulheres no agro. Corteva agriscience, 2019. Disponível em: https://www.corteva.com.br/mulheresnoagro.html. Acesso em: $1 \mathrm{dez}$ 2019. 
PROBST, E. R. A evolução da mulher no mercado de trabalho. Instituto Catarinense de Pós-Graduaçáo, ICPG. Santa Catarina, p.1-8, 2003.

RAMOS, C. P. Mulheres rurais atuando no fortalecimento da agricultura familiar local. Gênero, Niterói, v.15, n.1, p. 29-46, 2014.

REDIN, E. Família rural e produção de tabaco: estratégias de reprodução social em Arroio do Tigre/RS. 305 f. Tese (Doutorado em Extensão Rural) - Programa de Pósgraduação em Extensão Rural, Centro de Ciências Rurais, Departamento de Educação Agrícola e Extensão Rural, Universidade Federal de Santa Maria, Santa Maria, 2015.

REDIN, E. Jovem rural em questão. Sociais e Humanas, Santa Maria, v. 25, n.1, p. 123139, jan./jun. 2012.

SIMÓES, F. I. W.; HASHIMOTO, F. Mulher, mercado de trabalho e as configurações familiares do século XX. Vozes dos Vales, Diamantina, n. 2, p.1-25, 2012.

SISTEMA OCB. Cooperativas tem o papel de empoderar mulheres. Sistema OCB, 2018. Disponível em: https:/www.somoscooperativismo.coop.br/noticia/21029/cooperativastem-a-tarefa-de-empoderar-as-mulheres. Acesso em: $1 \mathrm{dez} 2019$.

TRIVINOS, A. N. S. Introduçáo à pesquisa em ciências sociais: a pesquisa qualitativa em educação. São Paulo: Atlas, 1987.

VILA, F.: Apresentação. In: CORDEIRO, A.; BIFF, M.; PAFFARO, R.; FIGUEIRÊDO, T. (ORGs). Mulheres do agro: inspiraçóes para vencer desafios dentro e fora da porteira. Belo Horizonte: Editora Letramento, 2019. p.15.

YANNOULAS, S. C. Dossiê: Políticas públicas e relações de gênero no mercado de trabalho. Brasília: CFEMEA, 2002. 93p. Disponível em: https://www.cfemea.org.br/ images/stories/publicacoes/dossiepprgmt.pdf. Acesso em: 12 dez. 2019. 